\title{
Notas SOBRE A CLÍNICA do TRAUMA
}

\author{
Silvia Lira Staccioli Castro ${ }^{\star}$ \\ Ana Maria Rudge $e^{\star}$
}

\section{RESUMO}

Discute-se a neurose traumática ilustrando-a com um caso clínico. Observando que adoecimentos psíquicos encontrados nos dias de hoje guardam semelhanças com aqueles tratados por Freud e outros psicanalistas na primeira metade do século $X X$, apresenta-se as idéias desses pioneiros. O caso clínico leva à observação de que o supereu é um instrumento conceitual importante para se privilegiar uma abordagem dinâmica no estudo psicanalítico da neurose traumática. A exacerbação da hostilidade do supereu é responsável tanto por aspectos da neurose traumática semelhantes à melancolia, quanto por idéias persecutórias que podem surgir a partir da projeção dos ditames superegoicos.

Palavras-chave: trauma; neurose traumática; angústia; supereu; clínica

\section{NOTES ON THE CLINIC OF TRAUMA}

\begin{abstract}
Traumatic neurosis is discussed and illustrated by a clinical case. Observing that psychic troubles found nowadays keep similarities with those treated by Freud and other psychoanalysts in the first half of the XX century, the ideas of those pioneers are briefly presented. The discussion of the clinical case shows that the superego is an important conceptual instrument to privilege a dynamic approach to traumatic neurosis. The exacerbation of superego's cruelty is responsible for some aspects of the traumatic neurosis similar to melancholy, as well as to paranoid ideas that may result from the projection of superego dictates.
\end{abstract}

Keywords: trauma; traumatic neurosis; anxiety; superego; clinic.

\footnotetext{
^Doutora e Mestre em Psicologia Clínica pela Pontifícia Universidade Católica do Rio de Janeiro. Psicanalista. Psicóloga oficial da Polícia Militar do Estado do Rio de Janeiro. Endereço: Avenida das Américas 2901- sl 1007- Barra Business - Barra da Tijuca - Rio de Janeiro - RJ - Brasil. CEP: 22631-002.

E-mail: silviaflira@yahoo.com.br

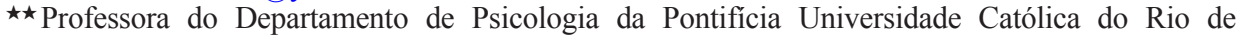
Janeiro. Pesquisadora do CNPq. Membro Psicanalista da Sociedade de Psicanálise Iracy Doyle. Pesquisadora da Associação Universitária de Psicopatologia Fundamental. Endereço: Marquês de São Vicente, 225; Edifício Cardeal Leme, sala 201. Gávea, 22453-900, Rio de Janeiro, RJ - Brasil. E-mail: arudge@puc-rio.br
} 
Embora o tema das novas formas de mal estar e patologias psíquicas esteja em voga, assim como as tentativas de teorizar sobre a nova clínica da contemporaneidade, atendimentos psicanalíticos prestados numa unidade militar com policiais feridos em combate nos mostraram o quanto é frequente a manifestação da "clássica" neurose traumática. O ambulatório de psicologia de um Batalhão da Polícia Militar do Estado do Rio de Janeiro (PMERJ) é procurado por muitos policiais, vítimas da neurose traumática. Nesses atendimentos, observações realizadas nas primeiras décadas do século passado que encontravam nos traumatizados de guerra sintomas semelhantes aos da melancolia se viram corroboradas.

Os policiais acompanhados psicoterapicamente, após terem passado por um grande trauma, encontravam-se à deriva, desgovernados, tendo já perdido o controle da situação de angústia e/ou depressão em que se viam. Padeciam dos seguintes sintomas: sonhos de angústia que reproduziam a experiência traumática; humor depressivo alternado com momentos de raiva; retração da libido manifesta em impotência ou diminuição do desejo sexual; desinvestimento dos objetos do mundo externo e hiperinvestimento do eu; isolamento social; indisposição para realizar qualquer atividade cotidiana, como se alimentar, sair de casa e dormir, condições necessárias para a própria sobrevivência humana. Buscavam ajuda para se localizarem em meio ao caos a que suas vidas havia se reduzido desde o trauma.

Observávamos nestes pacientes um enorme desejo de que o analista pudesse desvendar os enigmas trazidos pelo "não saber" sobre seu novo modo de estar no mundo, seu sofrimento, suas atitudes inadequadas e incompreensíveis, enfim, sobre seu novo eu. Eles tinham estranhas sensações corpóreas oriundas da violenta descarga de angústia que os desestabilizava. O surgimento involuntário de angústia desconcertava-os por ferir a suposta autonomia do eu; ela era a mais patente prova de não ser mais possível controlar as próprias reações emocionais após a vivência do incidente traumático.

O trauma resulta de um evento que inflige uma ferida narcísica, porque atesta a vulnerabilidade humana. Desse acontecimento inesperado pode advir uma neurose traumática, que não é, de forma alguma, uma mera revivescência de uma neurose infantil. O fato de ter estado vulnerável e impotente diante da possibilidade de morte pode levar o sujeito a enfrentar uma expectativa angustiada permanente. Foi-lhe mostrado pela vida que a segurança de que pensava desfrutar era ilusória; a partir disso tudo pode se tornar extremamente ameaçador.

A partir da clínica com soldados que retornaram gravemente doentes da $1^{\mathrm{a}}$. Grande Guerra, Freud deparou-se com uma nova sintomatologia, (ROUDINESCO; PLON, 1998, p. 277), semelhante àquela que acometia vítimas de graves acidentes ferroviários, e que havia sido batizada por Oppenheim (BERCHERIE, 1996[1983], p. 93) de neurose traumática. O psicanalista observou a presença de sintomas peculiares, como perturbações motoras, tais como as da histeria; sinais acentuados de indisposição subjetiva, como na melancolia e na hipocondria; debilitação e perturbação da capacidade mental; distúrbios do sono, isolamento social e indisposição para a realização de atividade física e intelectual, prevale- 
cendo fadiga e desânimo, entre outros sintomas de cunho depressivo. Era comum a ocorrência de terríveis pesadelos que reproduziam a vivência traumática passada em meio ao campo de batalha.

Comumente o neurótico de guerra apresentava uma retração da libido, já que a energia psíquica que investira os objetos do mundo exterior retornava para o eu, que ficava hiperinvestido. Ocorria então aquilo que Ferenczi (1921[1918]) chamou de hipersensibilidade do eu, condição que é também encontrada na hipocondria, e que se relaciona à incapacidade de suportar desprazer moral ou físico. Daí decorreu a opinião do psicanalista de que a neurose traumática é uma neurose narcísica.

$\mathrm{O}$ amor excessivo pelo eu derivava de uma regressão narcísica, ficando o doente numa posição de debilidade infantil. Isto explicaria, por exemplo, os distúrbios de marcha presentes nos militares egressos da guerra, que eram entendidos como formações defensivas contra a repetição da angústia. Estes distúrbios remontariam à época da infância anterior à aquisição do andar.

As neuroses narcísicas - neurose de guerra, demência precoce, paranóia e melancolia - para o psicanalista húngaro, deveriam ser descritas a partir dos seguintes sintomas - depressão hipocondríaca devida ao hiperinvestimento no eu; pusilanimidade; angústia; excitabilidade elevada acompanhada de acessos de cólera; hiperestesia de todos os órgãos de sentido (fotofobia, hiperacusia, hiperestesia cutânea intensa) e sonhos de angústia.

Médico e psicanalista adepto da hipnose, Simmel (1921[1918]) esteve por dois anos à frente de um hospital militar do exército alemão durante a $1^{\mathrm{a}}$. Guerra Mundial (FREUD, 1975[1919], p. 214), que atendeu cerca de dois mil neuróticos de guerra. Eles apresentavam o seguinte quadro clínico: distúrbios do âmbito motor e cognitivo que impediam o cumprimento das obrigações militares, como a alteração das condições de todo o sistema muscular ou de partes do mesmo, que diminuíam em maior ou menor grau a capacidade do soldado de mover-se. O distúrbio motor manifestava-se amiúde sob a forma de movimentos ou posturas do corpo involuntárias e compulsivas e, às vezes, como transtornos da fala que às vezes chegavam ao total mutismo. Havia também casos de transtornos de órgãos de sentido, da visão e da audição, que variavam da hipersensibilidade à luz ou ao som até à completa cegueira e surdez, prejudicando o contato com o mundo. Seus estudos mencionam ainda casos de soldados afetados por ataques epileptiformes, e com transtornos na esfera intelectual que englobavam desde a perda de determinadas faculdades mentais como a leitura e o cálculo, até alterações funcionais da memória que podiam chegar até a amnésia total.

Em seu texto apresentado no Congresso Internacional de Psicanálise em 1918, Simmel (1921[1918]) explicou a origem da neurose de guerra a partir da premissa freudiana de que o eu do soldado, dividido entre um eu pacífico de um lado e um eu guerreiro de outro, tem de atuar como mediador das demandas pulsionais em relação às exigências da realidade externa. A entrada numa guerra produz no soldado uma cisão do eu, pois, ao mesmo tempo em que ele tem que ser camarada com seus pares, sacrificando-se, espera-se dele virtudes antisociais, 
isto é, violência suficiente para ferir e matar. Estar diante da perspectiva de uma aniquilação completa torna o eu do soldado vulnerável. Este é um fator decisivo, na opinião do autor, para que se constitua uma neurose de guerra.

Em uma guerra, como os valores compartilhados pelos grupos combatentes são antagônicos àqueles pregados culturalmente, o sujeito perde a possibilidade de pacificar suas moções pulsionais destrutivas. Sendo assim, o sujeito se vê pronto a atender à demanda da pulsão de morte, ante a qual, antes da guerra, era levado a resistir devido às exigências impostas pela cultura. Esse novo panorama pode levar o soldado a adoecer, justamente por causa da perda da capacidade de mediação do conflito entre as pulsões e a realidade externa, isto é, entre o mundo interior e o exterior.

Embora Simmel fosse adepto da idéia freudiana de tomar a neurose de guerra como um caso de neurose traumática, o autor buscou estabelecer as conseqüências do trauma para um eu militar, diferenciando-as daquelas sofridas por um eu civil. Isto porque acreditava que, devido à lavagem cerebral operada na formação militar, ocorreria uma alteração significativa na constituição psíquica do militar. Em sua visão, o militar externaliza na figura do chefe não somente seu ideal do eu, como Freud propôs em 1921, mas seu supereu. Para defender esta tese, o autor faz a seguinte pergunta retórica: por que a unidade combatente recebe o nome de infantaria? (SIMMEL, 1921[1918]).

O eu do militar, por esta razão, seria especialmente vulnerável a uma desintegração de sua estrutura, e a consequentes desordens psíquicas. Em sua opinião, as neuroses de guerra, ao contrário das neuroses traumáticas de tempos de paz, não são desencadeadas pelo impacto de um súbito acidente catastrófico, mas devido a uma acumulação de influências traumáticas, já que, embora o soldado esteja preparado para enfrentar uma condição de estresse que o civil não poderia suportar, se o período de exposição a condições típicas de um campo de batalha é excessivamente longo, o militar pode atingir um esgotamento físico e emocional de tal magnitude que resulte num severo colapso mental.

Para corroborar sua tese, Simmel (1921[1918]) recorre a alguns casos de soldados que adoeceram logo após passarem por situações de choque de proporção insignificante em relação a experiências anteriores que aparentemente não haviam gerado nenhuma reação psicológica imediata.

No entanto, o próprio Freud (1996[1939]) referiu-se a um "período de incubação", chamado também de "período de latência", que seria o tempo decorrente entre o acontecimento traumático e o primeiro sinal da neurose traumática. A pessoa saía aparentemente ilesa de um grave acidente, porém, com o passar do tempo, desenvolvia uma série de sintomas que pareciam estar ligados ao episódio violento vivido anteriormente.

Segundo Simmel (1921[1918]), dentre todos os sintomas observados em sua prática clínica, aqueles especialmente comuns nas neuroses de guerra são: instabilidade e irritabilidade emocional gerais; tendência a rompantes emotivos, sobretudo de ira; e, por último, transtorno característico do sono, pautado 
pela alta incidência de pesadelos que reproduzem as dolorosas experiências de guerra, levando frequentemente o sonhador a atuar impulsivamente sem acordar, em episódios de sonambulismo.

De acordo com sua teoria, o eu militar tem a tendência a empregar uma reação de defesa que é a de romper com a realidade como efeito imediato da exposição às experiências terríveis de guerra, como ocorria nos estados de desfalecimento temporário e estupor comatoso de longa duração apresentados pelos soldados oriundos das trincheiras da $1^{\mathrm{a}}$. Guerra (SIMMEL, 1921[1918]). Esse mecanismo pode levar à produção, com muita frequência, de transtornos de personalidade que se parecem com os encontrados na psicose.

Hardcastle (1944) também publicou estudo sobre os neuróticos de guerra, de quem cuidou no Hospital de Ortopedia do Exército inglês. Ele comandou uma ala de psiquiatria durante a guerra, que acomodava cerca de 80 homens, todos acometidos por neurose traumática. Estes pacientes apresentavam um estado crônico de angústia e depressão. Mostravam-se inibidos, e o interesse pelo sexo havia diminuído expressivamente em todos eles, havendo inclusive casos de impotência sexual e ausência completa de desejo chamada pelo autor de aphanisis.

A sua clínica era fundada na hipnose, e ele utilizava uma técnica bem semelhante ao método catártico fora empregado por Breuer e Freud. Daí Ferenczi (1921) ter nomeado esta técnica terapêutica de psicocatarse. Consistia em fazer com que o paciente falasse sobre suas experiências na guerra, especialmente aquelas que constituíam o tema dos pesadelos que se repetiam ad nauseum, provocando angústia intensa. Deste modo, a hipnose era empregada para recuperar lapsos de memória que podiam ter ligação com o advento da doença. Através desta prática, esperavase que o paciente pudesse dar uma resposta adequada ao trauma. Valorizando uma perspectiva predominantemente econômica, o autor considerava que, sob hipnose, o sujeito poderia vir a abreagir o afeto que ficara estrangulado no trauma, tal como estabelecera a teoria pré-psicanalítica formulada por Breuer e Freud.

Hardcastle (1944) observou primeiramente ser errônea a afirmação de que a neurose traumática seria uma reação para se evadir da zona de guerra. Isto porque naquela época a guerra já havia terminado, e a maioria dos pacientes, apesar do desejo de retornar para suas casas, ainda não tinha condições para isso. Presos no passado como se o tempo tivesse sido interrompido no momento do trauma, eram, para usar a expressão de Braunstein (2003), mortos-vivos. De fato, eles estavam identificados com o morto, apagados subjetivamente, como se a ameaça de aniquilamento físico houvesse gerado uma experiência de aniquilamento psíquico. Pairava sobre o sujeito uma sombra, como na melancolia. A tristeza profunda e a falta de vontade de viver são muito marcantes na neurose traumática.

Além disso, muitos dos comportamentos dos internados pareciam indicar um estado de expectativa angustiada, semelhante àquele a que estiveram sujeitos durante a guerra. Assim, qualquer barulho repentino provocava uma reação de defesa imediata. Até mesmo o andar de alguns deles lembrava a forma como se locomoviam no front. O fenômeno das dores, que podemos qualificar de "fantasmas", é tomado como um sintoma primordial de neurose traumática. Eram dores 
que não tinham quaisquer motivações físicas; remetiam exclusivamente à experiência traumática, como uma espécie de memória fixada, pois eram condizentes com a condição física do sujeito no momento do trauma. Para fornecer uma idéia mais precisa deste quadro, o autor apresenta o caso de um homem que havia se ferido quando escapava de um navio em chamas, atingido por um submarino inimigo. Ele costumava apresentar uma "equimose" nas duas pernas toda vez que sonhava com o que lhe havia ocorrido.

A reprodução da situação traumática engendrada pelos sonhos de repetição levava não só a um estado de angústia e depressão, mas também era responsável pela manifestação de sinais físicos que pareciam indicar que o sujeito de fato revivia, através destes pesadelos, a experiência do trauma, do qual trazia consigo marcas indeléveis.

Contrariamente à opinião freudiana, Hardcastle (1944) acreditava que a etiologia da neurose traumática localizava-se na infância. Segundo seu ponto de vista, o adoecimento não era gerado primordialmente pela vivência de uma situação contingente que havia evocado o desamparo, mas o evento teria sido apenas o estopim para a atualização e reedição de uma neurose infantil.

Já Freud (1920), quando assinalou o humor depressivo nas neuroses traumáticas, denunciava a dessexualização, apontando para o papel da pulsão de morte nesse quadro clínico específico. Ele aproximou a neurose traumática da melancolia quanto a este tipo de mal estar. Entre os motivos que levaram Freud a fazer essa aproximação, parece-nos que têm lugar importante os ditames cruéis do supereu que massacram o eu tanto na primeira enfermidade como na segunda. O humor depressivo e a retração da libido são comuns às duas patologias.

Como Freud (1915) notara, não existe representação inconsciente da morte. Num acidente envolvendo grande perigo de vida, a percepção do risco e da proximidade da morte provoca um completo estado de desamparo. A ameaça de morte é revivida por incontáveis vezes após o trauma, numa literalidade que é característica da neurose traumática, e que não se encontra em sintomas das neuroses clássicas. O retorno involuntário das lembranças dolorosas fazem o sujeito acreditar que, do fim da vida, não poderá escapar novamente.

A revolta por ter acreditado numa ficção, o fracasso da fantasia de estar amparado e protegido, levam a intensos rompantes de ira, que podem chegar a perturbar o andamento da análise, quando a transferência negativa se torna muito intensa. Como o paciente não suporta defrontar-se com um Outro falho, insuficiente para garantir sua segurança, ele elege um Outro inteiro, completo e extremamente ameaçador, que carrega o sadismo do supereu que se voltou contra o eu após o trauma, vindo a construir um delírio paranoide. Não se trata de um delírio paranoico propriamente dito, já que não há a certeza de estar sendo perseguido; resta sempre uma dúvida, em se tratando de um neurótico.

Depois de certo tempo decorrido da vivência traumática, nossa experiência clínica mostra que o paciente pode encontrar-se em um estado paranoide sem que seja psicótico, tomado pela sensação de que está sendo vigiado e seguido por 
quem pretende destruir tudo que é seu, sua vida, a de seus familiares... Em última instância, sua sanidade. Não tem mais nenhuma tranquilidade, atormentado pela angústia que comparece através do real do corpo, sinalizando não ser possível esconder os indícios de uma aflição aterrorizante e a impressão de que o pior ainda está por vir. Embora essa ameaça de morte seja considerada como externa, ela não vem de fora, como supõe o sujeito, ela é produzida internamente, pelo supereu.

A introdução do supereu no estudo do trauma permite abordarmos o sintoma traumático de uma perspectiva dinâmica, ponto de vista que não poderia ser adotado se mantivéssemos apenas a idéia do susto (Schreck), do excesso pulsional, do quantum de energia que invade o aparelho psíquico, dentro da concepção metafórica proposta por Freud em 1920 para explicar a sintomatologia da neurose traumática, de uma vesícula protetora de estímulos que foi rompida. Vale notar que essa metáfora se deve ao fato de que o termo trauma veio originalmente da medicina, para designar ferimentos em que tecidos eram efetivamente rompidos.

Os aspectos depressivos da neurose traumática frequentam a literatura, remetendo à exacerbação da virulência do supereu. É também a essa exacerbação do supereu que se devem as vivências paranóides encontradas na clínica, em que essa hostilidade superegóica é projetada.

A angústia na neurose traumática pode levar ao suicídio. Sabemos que, quando o trauma resulta de uma experiência de ter estado a um passo da morte, resta a convicção de que a sobrevivência foi fruto de um verdadeiro milagre. $\mathrm{O}$ que fica impossível compreender não é a magnitude da tragédia, mas sim a sorte de ter escapado dela com vida.

\begin{abstract}
É porque a mente não pode confrontar a possibilidade de sua própria morte diretamente, que a sobrevivência se torna para o ser humano, paradoxalmente, um eterno testemunho da impossibilidade de existência (CARUTH, 1999, p. 62, tradução nossa).
\end{abstract}

Conforme a autora, o que retorna nos flashbacks não é a incompreensão de ter estado tão perto da morte, mas a de ter sobrevivido a ela (CARUTH, 1999). É difícil acreditar que se tenha escapado ileso do acidente, especialmente quando outros não receberam esse favor do destino, o que induz sempre ao incremento da culpa.

Em alguns casos, ao invés de ocorrer um trabalho de luto para enterrar o que foi perdido com o trauma, o agravamento do poder sádico do supereu engendra um processo de compulsão à repetição que conduz o sujeito à autodestruição.

$\mathrm{O}$ trauma pode pôr em funcionamento um supereu tirânico que se alimenta da pulsão de morte, exortando o sujeito ao gozo via repetição, submetendo-o obedientemente a uma satisfação masoquista que compromete a sua saúde mental. De fato, como ressaltou Lacan (1998[1963]), o supereu é desconectado de toda e qualquer noção de moralidade, e não se confunde com o ideal do eu. Em seu estudo sobre o tema, Lacan evocou a Lei do Gozo ditada pelo supereu, observando que ele pode assumir o aspecto de um "Ser-Supremo-em-Maldade"(LACAN, 1998[1963]). 
Na neurose traumática, o supereu faz do eu sua vítima. Nestas circunstâncias, o imperativo categórico impõe ditames destrutivos. O supereu cria verdadeiras armadilhas para o eu que, em última análise, levariam à morte, completando a ação que não foi finalizada quando do evento traumático. Ocorre então uma demanda de trabalho da pulsão de morte à vida anímica para que a ameaça de aniquilamento psíquico, motivada pelo trauma, se realize de fato. Não é incomum que, após o choque, o paciente venha a adotar atitudes drásticas e intempestivas, como, por exemplo, romper com a namorada, pôr fim ao casamento, sair de casa, etc. Antes que seja abandonado pelo outro, como teme, ele o abandona, desfazendo seus laços afetivos, substituindo a passividade pela atividade. Todavia, desta forma acaba satisfazendo o gozo, pois vivencia outras perdas, vindo a sofrer ainda mais. Este funcionamento, que está além do princípio de prazer, parece ser motivado pelo sentimento de culpa inconsciente. Daí o drama dos sobreviventes dos campos de concentração nazista que, após serem libertados, vieram a se suicidar, provavelmente atormentados pelo doloroso sentimento de culpa por terem sobrevivido, ao contrário dos milhares de companheiros falecidos, entre eles, amigos e parentes. Embora tenham escapado do inferno, sofriam dilacerados pelas lembranças pavorosas daquela cruel experiência vivida na guerra.

Desta maneira, o sadismo e a crueldade do supereu a serviço da pulsão de morte podem perder sua medida na neurose traumática, levando o sujeito a atuações danosas para si mesmo. Do trauma pode advir um luto bem-sucedido, ou um extremo mal-estar que compromete o futuro do sujeito, conforme será exposto no caso clínico.

\section{Vinheta CLÍNICA}

Júlio procurou tratamento no ambulatório de psicologia após ter sofrido um tenebroso acidente, cuja lembrança ecoava em sua mente impedindo que pudesse seguir com sua vida normalmente. Compareceu à primeira entrevista disposto a contar tudo o que havia lhe acontecido. Era preciso falar, contar como havia sobrevivido ao massacre. Aflito, em muitos momentos ficava com a respiração alterada, ofegante, nervoso, cheio de sentimentos conflitantes dentro de si. Buscava uma saída para escapar da prisão causada pelo pensamento ruminante de morte, que o devastava por dentro.

$\mathrm{O}$ seu relato foi bastante emocionado e o transportou de imediato à situação traumática, caótica e desesperadora, vivida subitamente num dia comum de trabalho. Retornava de uma missão num ônibus da Polícia Militar, quando o veículo foi atacado por muitas balas de fuzil que atingiram um a um do grupo. Júlio ainda pensou em saltar do ônibus em movimento, mas quando se aproximou da porta de entrada, foi atingido na barriga. O motorista também foi baleado, vindo a desmaiar sobre o volante, perdendo o controle do ônibus, que caiu numa vala de esgoto. Neste meio tempo, Júlio foi projetado para fora do veículo e ficou parcialmente preso embaixo do ônibus. O peso do veículo impedia que seu resgate fosse realizado. Então, ele ficou por horas a fio aguardando socorro naquela água fétida, sentindo uma dor dilacerante. Perdia tanto sangue pelo ferimento em sua 
barriga que suspeitava não poder sair vivo dali, chegando a perder a consciência. No entanto, lutou corajosamente por sua vida, salva pela chegada do Caveirão (veículo blindado) do Batalhão de Operações Especiais (BOPE), que trazia homens da tropa de elite para dar apoio aos policiais encurralados no canal de esgoto. O ônibus foi então amarrado ao blindado, que serviu como guincho, puxando o veículo para fora da água, e finalmente foi possível libertar Júlio.

No hospital deram sua morte como certa. Para sua esposa, disseram que era melhor que se preparasse para o pior, pois o estado de saúde do seu marido era muito grave, tirando-lhe todas as esperanças. Quando acordou, muitas horas depois do acidente, ele descobriu que todos os seus objetos pessoais, que estavam numa bolsa presa ao seu corpo no momento do acidente, haviam desaparecido. Sentiu, então, desgosto e ódio profundos. Afinal, como poderia ter sido furtado estando sob proteção dos colegas policiais? A única justificativa que pôde encontrar para tal atitude foi a de que os responsáveis pelo roubo suspeitavam que ele não sobreviveria.

Desde que sofrera o severo acidente, vinha tendo muitos pesadelos que repetiam em todos os detalhes aqueles dolorosos momentos de angústia vividos no ataque feito à sua vida. Eram tão reais e intensos que o levavam ao desespero. A angústia era tamanha que o fazia, estando adormecido, socar o travesseiro e até chutar sua esposa, que dormia ao seu lado. Passado um tempo em análise, esses sonhos monocórdios cessaram. Então surgiram outros em que passava por situações tão penosas quanto as da circunstância do acidente. Curiosamente, sempre estava sob ameaça de morte, em troca de tiros ou fugindo da perseguição de algum bandido. Acordava todo suado, em pânico, com a sensação de estar à beira da morte. Seu sono ficou bastante perturbado, chegando ao ponto de ter medo de dormir. Procurava, então, se deitar de dia, porque assim se sentia mais seguro.

Com o tempo, a sensação de estar sendo perseguido foi aumentando, tornando-se mais consistente. Passou a sofrer de um transtorno delirante do tipo persecutório. Assim, queixava-se de estar sendo caçado por pessoas que queriam matá-lo, e que sabiam onde ele morava. Estava à beira de um ataque de nervos.

Havia sido baleado e usurpado, como comentou um dia, "ficado na merda" e dela parecia nunca ter saído. Isto parecia impossível de ocorrer com um PM que sempre tinha sido visto como "vibrador", adjetivo que é dado aos PMs entusiasmados com sua missão. Trazia, para a analista, antigas reportagens que informavam sobre o seu bom desempenho em nome da PMERJ. Júlio orgulhava-se por ter sido elogiado inúmeras vezes pela Corporação e homenageado outras tantas por bravura. Ele fazia desse modo uma tentativa de reconstruir sua imagem que fora mutilada, supondo ter a analista um saber sobre como recuperar o que fora perdido - não só a mobilidade e saúde de seu corpo, como a integridade de seu eu.

Estava "desiludido" com a Polícia Militar, pela qual fizera tanto e tão pouco estava recebendo em troca. Revoltava-se com a impotência da Corporação, que não havia conseguido proteger adequadamente seu membro. 
Quando a fantasia de que a Corporação lhe oferecia toda a segurança caiu, Júlio defrontou-se com a consciência de que fora uma ilusão acreditar-se protegido. Ele não sabia como lidar com a aparição da falência do Outro, desse Outro não todo. Ser policial era um sonho de infância. Havia conquistado este ideal, mas naquele momento essa imagem não tinha mais valor, deixando-o desamparado. Observamos que na construção delirante paranóide havia uma tentativa de restaurar a imagem de um Outro inteiro/completo, que antes pertencera à Polícia Militar e que fora desfeita.

A exposição da insuficiência da organização policial militar causou-lhe intenso mal-estar. Era como se suas referências subjetivas mais importantes estivessem ruindo. Uma vez em licença para tratamento de saúde, havia sido excluído do grupo de combatentes. Isto fez com que ele perdesse o lugar no coletivo, rompendo a ligação afetiva com seus pares e com seu chefe. $\mathrm{O}$ amor que os unira por tantos anos havia sido posto em xeque, fazendo com que a manutenção do eu sustentada pela instituição total se tornasse falha e precária.

Nem os cuidados médicos que lhe eram prestados pareciam ser suficientes para cobrir o buraco que ficara à mostra. Júlio havia perdido não somente sua capacidade produtiva, mas junto com ela, sua própria identidade. Não reconhecia mais o que havia sobrado de si mesmo após o acidente. Seu corpo havia sido cortado em dois e a costura na pele, mostrada à analista na primeira sessão, denunciava o trauma.

Não aceitava estar naquela situação, não admitia ter sequelas, clamava por algo que aliviasse sua dor. Para a analista era claro que o paciente demandava uma restituição de natureza narcísica. Tudo que havia sofrido representava um grande golpe, uma decepção consigo mesmo e com a Corporação, uma ferida impossível de cicatrizar. Desde então, sua vida havia "se transformado em lama", realidade da qual não conseguia sair.

Numa sessão disse à analista que parecia carregar consigo uma espécie de ímã que atraía somente coisas ruins para si. Tudo estava saindo do eixo. Apesar de nunca ter verbalizado isso explicitamente, parecia perguntar qual era sua parcela de culpa para que o destino tivesse sido tão cruel com ele, castigando-o daquele jeito. Acreditava estar sendo punido por tudo o que já havia feito de errado na vida. Era hora de pagar por seus excessos.

Conforme ensinou Freud (1996[1924], p. 185), a última figura na série de imagos que constituem o supereu, iniciada com os pais, é o próprio destino, cujo poder sombrio "apenas poucos dentre nós são capazes de encarar como impessoal". Para a grande maioria das pessoas, ele não passa de uma projeção tardia do pai (FREUD, 1996[1928]).

O eu, como mostrou Reik (1997), tende a vislumbrar outra ameaça por trás do perigo externo. O perigo reativa o medo do supereu, que sempre assume a forma de medo da morte, esteja a vida do sujeito realmente em perigo ou não. 
Tendo sofrido um choque e uma violência inesperados, o eu sente-se abandonado pelo supereu, desfazendo-se assim a certeza de ser amado e protegido que o acompanhava desde a infância A perda desta segurança, que é uma ilusão, deixa o sujeito sem chão. O evento traumático impõe uma fratura ao eu, uma brusca perturbação do equilíbrio libidinal narcísico.

O choque abala de chofre a independência relativa que o eu havia adquirido face ao supereu. É como se a violência do trauma trouxesse à baila a potência destrutiva do supereu, projetado no mundo exterior sob a forma do destino. Assim, é sob a forma de um castigo que o sofrimento é enfrentado: o que fiz eu para merecer isso?

Vimos neste caso que o trauma pode acarretar fenômenos próximos aos verificados na psicose, como a despersonalização. Há um verdadeiro estranhamento em relação à nova imagem egóica, que, no caso desse paciente, se tornou a de um homem frágil e amedrontado. A sensação que habita o sujeito traumatizado é a de não ser mais o mesmo.

Freud (1920)estabeleceu aproximações entre a neurose traumática e a histeria, e também entre a melancolia e a neurose traumática, o que nos permite concluir que as duas últimas podem ser tomadas como "neuroses narcísicas":

O quadro sintomático apresentado pela neurose traumática aproxima-se do da histeria pela abundância de seus sintomas motores semelhantes; em geral, contudo, ultrapassa-o em seus sinais fortemente acentuados de indisposição subjetiva (no que se assemelha à hipocondria ou melancolia), bem como nas provas que fornece de debilitamento e de perturbação muito mais abrangentes e gerais das capacidades mentais. (FREUD, 1920, p. 12)

Como ficou patente nesse caso clínico, a neurose traumática pode também aproximar-se da paranóia, quando o ataque superegóico que causa a indisposição subjetiva é projetado.

Decerto, a análise é o lugar por excelência para se tratar do trauma, pois incita o sujeito a elaborar o que ficou de fora da cadeia de significante, como um signo isolado, e que insiste em retornar causando angústia. Se a fantasia foi estilhaçada pelo encontro com o real traumático, o trabalho analítico pode atenuar seu impacto desestruturante. $\mathrm{O}$ amor de transferência pode ser propício à reconstrução da esfera das fantasias e das narrativas que constituem o eu, possibilitando a ligação daquilo que ficou de fora do pensamento.

Assim, o analista deve possibilitar que brotem do analisando as palavras que vão preencher as lacunas do que antes era indizível, pois ele está ali, emprestando sua voz e seu corpo como testemunha da violência do trauma, tornando-o menos absurdo e menos irreal. $\mathrm{O}$ amor de transferência pode barrar o gozo do supereu sádico (FUKS, 2001), retirando o sujeito da compulsão à repetição do trauma. 
Invariavelmente, a clínica com pacientes traumatizados provocará angústia no analista. Sabemos como é difícil encarar os encontros com um real contingente, imprevisível e insuportável na vida do outro, pois ele nos remete às nossas próprias feridas narcísicas e a nosso desamparo ante o destino. É uma tarefa que custa caro ao psicanalista, mas, como Freud já nos advertiu, psicanalisar é uma das tarefas impossíveis. Por isso mesmo, algum material relativo ao trauma possivelmente permanecerá com o analista à espera de uma elaboração.

\section{Nota}

${ }^{1}$ Ao elaborar a $2^{\mathrm{a}}$ tópica, no pequeno artigo Neurose e Psicose, Freud (1924 [1923] diferencia esquematicamente 1. neurose, em que o conflito entre pulsão e realidade leva ao recalque da pulsão, 2. psicose, em que a defesa é contra a realidade, a favor da pulsão e 3. o que chamará de neurose narcísica, resultante de um conflito entre eu e supereu, que tem a melancolia como paradigma.

\section{REFERÊNCIAS}

BERCHERIE, P. Génesis de los Conceptos Freudianos (1983). Buenos Aires: Paidos, 1996.

BRAUSTEIN, N. A. Sobrevivendo ao trauma. Tempo Psicanalítico, Rio de Janeiro, v. 35, p. 93-114, 2003.

CARUTH, C. Unclaimed experience: trauma, narrative and history. London: The John Hopkins University, 1999.

FERENCZI, S. Psychoanalysis and the War Neurosis (1918). In: FERENCZI, et al. Psychoanalysis and the War Neurosis. London, Vienna, New York: The International PsychoAnalytic, 1921. v. 2, p. 5-21.

FREUD, S. Thoughts for the times on war and death (1915). In: The

Standard Edition of the Complete Psychological Works of Sigmund Freud. London: Hogarth 1975. v. 14, p. 273-300.

FREUD, S. Introduction to Psycho-Analysis and the War-Neuroses (1919). In: . The Standard Edition of the Complete Psychological Works of Sigmund Freud. London: Hogarth, 1975. v. 17, p. 205-216.

FREUD, S. Beyond the Pleasure Principle. The Standard Edition of the Complete Psychological Works of Sigmund Freud. London: Hogarth, 1920. v 18, p. 1-64.

FREUD, S. Psicologia do grupo e a análise do ego (1921). In . Obras

Psicológicas Completas de Sigmund Freud. Rio de Janeiro: Imago, 1996. v. 17, p. 89-179. Edição Standard Brasileira. 
FREUD, S. Neurosis and psychosis (1923). In . The Standard Edition of the Complete Psychological Works of Sigmund Freud. London: Hogarth, 1924. v. 19, p. 147-153.

FREUD, S. O problema econômico do masoquismo (1924). In: . Obras Psicológicas Completas de Sigmund Freud. Rio de Janeiro: Imago, 1996. v. 19, p. 197-214. Edição Standard Brasileira.

FREUD, S. Dostoievski e o parricídio (1928[1927]). In: . Obras Psicológicas Completas de Sigmund Freud. Rio de Janeiro: Imago, 1996. v. 11, p. 181-200. Edição Standard Brasileira.

FREUD, S. Moisés e o Monoteísmo (1939[1934-38]). In: . Obras Psicológicas Completas de Sigmund Freud. Rio de Janeiro: Imago, 1996. v. 23, p. 7-137. Edição Standard Brasileira.

FUKS, B, B. Notas sobre o conceito de angústia. Revista Estudos e Pesquisas em Psicologia, Rio de Janeiro, v. 1, n. 1, p. 1-9. 2001.

HARDCASTLE, D. N. Some notes on traumatic neurosis and allied conditions. International Journal of Psychoanalysis, London, v. 25, n. 3-4, p. 132-142, 1944.

LACAN, J. Kant com Sade (1963). In: . Escritos. Rio de Janeiro: J. Zahar. 1998. p. 776-803.

SIMMEL, E. Psychoanalysis and the War Neurosis In: SYMPOSIUM ON PSYCHOANALYSIS AND THE WAR NEUROSIS. 1918, Budapest. Fifth International Psycho-Analytical Congress Budapest, Budapest: International Psycho-Analytical Library, 1921. v. 2, p. 30-43.

REIK, T. Le Besoin d'Avouer: psychanalyse du crime et du châtiment. Paris: Payot, 1997.

ROUDINESCO, E.; PLON, M. Dicionário de Psicanálise. Rio de Janeiro: J. Zahar, 1998

Recebido em: 03 de abril de 2010 Aceito em: 01 de fevereiro de 2012 
